Article

\title{
Takotsubo Cardiomyopathy: A Long Term Follow-up Shows Benefit with Risk Factor Reduction
}

\section{Koroush Khalighi ${ }^{1, *}$, Mohammad Umar Farooq ${ }^{2, \dagger}$, Thein Tun Aung ${ }^{3, \dagger}$ and Swe Oo ${ }^{4, \dagger}$}

1 Department of Cardiovascular Disease, Easton Hospital Easton, PA Clinical Professor of Medicine, Drexel University, School of Medicine Easton Cardiovascular Associates 2001 Fairview Ave, Easton, PA 18042, USA

2 Department of Medicine, Easton Hospital, 250 South 21 street, Easton, PA 18042, USA; E-Mail: Mohammad_Farooq@chs.net

3 Department of Cardiovascular Disease, Wright State University, 921 Wilmington Ave, Apt D, Dayton, OH 45420, USA; E-Mail: theintun.aung@hotmail.com

4 Department of Medicine, Easton Hospital, 250 South 21 street, Easton, PA 18042, USA; E-Mail: swezin82@gmail.com

$\dagger$ These authors contributed equally to this work.

* Author to whom correspondence should be addressed; E-Mail: koroushkhalighi@gmail.com; Tel.: +1-484-903-9926

Academic Editor: Andy Wessels

Received: 6 July 2015 / Accepted: 6 November 2015 / Published: 16 November 2015

\begin{abstract}
Only sparse data was available on long-term of Takotusbo Cardiomyopathy (TC). Previous studies suggested prognosis is not necessarily benign. We report the long-term follow-up of $12 \mathrm{TC}$ patients actively managed with risk factor reduction. Retrospective analysis of all patients diagnosed with TC at our hospital between 1998 and 2010. We identified 12 patients with TC among 1651 cases of emergent left heart catheterization over 12 years. Mean follow-up time was $8.3 \pm 3.6$ years. All were female, $87 \%$ had hypertension, $25 \%$ had history of Coronary Artery Disease (CAD), 67\% had hyperlipidemia, $44 \%$ had some preceding emotional trauma, and $44 \%$ had some physical/physiological stress. Previous studies have shown that over $50 \%$ of TC patients experience future cardiac events, and $10 \%$ have a recurrence of TC. Patients were prescribed therapeutic lifestyle changes (TLC) and guideline directed medical therapy
\end{abstract}


(GDMT) for aggressive risk factor reduction. TLC included diet, exercise, and cardiac rehabilitation. GDMT often included aspirin, beta-blockers, ACE-inhibitors, and statins. Follow-up echocardiograms showed recovery and maintenance of the ejection fraction. There was no cardiac mortality and no recurrences of TC. Aggressive risk factor reduction with TLC and GDMT may be effective in improving the long term outcomes of patients with TC.

Keywords: Takotusbo Cardiomyopathy (TC); Myocardial Infarction with Normal Coronary Arteries (MINCA); stress-induced cardiomyopathy; Coronary Artery Disease (CAD)

\section{Introduction}

Takotsubo Cardiomyopathy (TC) was first described in 1991 in Japan. It consists of transient systolic dysfunction of the apical and/or mid-segment of the left ventricle, a clinical presentation of that mimics acute myocardial infarction and absence of obstructive coronary artery disease. Sparse data available on long-term outcomes suggests prognosis is not necessarily benign. We report the long-term follow-up of 12 TC patients, and speculate that intensive risk factor modification may account for the good outcomes we observed in this group.

\section{Methods}

From January 1998 to December 2010, among 1651 who underwent emergent left heart catheterization for acute coronary syndrome (ACS), 12 patients were identified with having TC using the Modified Mayo Criteria. Main components include akinesia of mid-distal LV, non-obstructive Coronary Artery Disease (CAD), new EKG changes, and absence of myocarditis or pheochromocytoma (Table 1).

Table 1. Demographic Characteristics.

\begin{tabular}{ccccccccc}
\hline $\begin{array}{c}\text { Patient } \\
\text { Number }\end{array}$ & $\begin{array}{c}\text { Follow up } \\
\text { (Years) }\end{array}$ & Age (Year) & Sex & HTN & DM & CAD & Dyslipidemia & FH CAD \\
\hline A & 13 & 57 & F & No & No & No & Yes & Yes \\
B & 17 & 36 & F & No & No & No & Yes & Yes \\
C & 9 & 67 & F & No & No & No & No & No \\
D & 8 & 72 & F & Yes & No & No & Yes & No \\
E & 7 & 61 & F & No & No & Yes & Yes & No \\
F & 10 & 89 & F & Yes & No & No & No & No \\
G & 6 & 41 & F & Yes & No & No & No & No \\
H & 6 & 69 & F & Yes & No & Yes & Yes & Yes \\
I & 5 & 69 & F & Yes & No & Yes & Yes & Yes \\
J & 5 & 81 & F & Yes & Yes & No & Yes & No \\
K & 5 & 56 & F & Yes & Yes & No & Yes & Yes \\
L & 8 & 65 & F & Yes & No & Yes & Yes & Yes \\
& & & $100 \%$ F & $75 \%$ & $17 \%$ & $25 \%$ & $67 \%$ & $50 \%$ \\
\hline
\end{tabular}


All patients underwent follow-up evaluation of left ventricular function with transthoracic echocardiogram six weeks after the initial event, followed by yearly echocardiograms. We followed these 12 patients, who were actively managed with both lifestyle modification and pharmacologic treatment, over the 5-17 years period after the initial TC event.

Patients were advised regarding therapeutic lifestyle changes (TLC) and prescribed guidelinedirected medical therapy (GDMT) for aggressive risk factor reduction. TLC included low-salt, low-fat diet, exercise, and cardiac rehabilitation. GDMT often included anti-platelet agents (aspirin, clopidogrel), beta-blockers (metoprolol or carvedilol), angiotensin converting enzyme inhibitors (ACEI) (lisinopril or ramipril), and statins (atorvastatin). The primary end point was a combination of all-cause death, cardiogenic shock, sudden cardiac death, recurrence of TC, and re-hospitalization for cardiac reasons.

\section{Results}

All of the patients in our study were female and most were post-menopausal with a median age of 66 years (ranging from 36 to 89 years). Many had risk factors for coronary artery disease (CAD) with 75\% (9/12) having hypertension, 67\% (9/12) with hyperlipidemia, and 50\% (6/12) with a family history of CAD. There were $25 \%$ (4/12) who already had a documented history of CAD. On presentation, $58 \%(7 / 12)$ had preceding emotional trauma and 50\% (6/12) had physical stress (Tables 1 and 2$)$. All patients presented with chest pain and troponin elevation, while 50\% (6/12) had ST elevations on EKG. Coronary angiography revealed no obstructive lesion and left ventriculography revealed apical hypokinesis along with decreased ejection fraction (EF) in all patients (Table 2).

Table 2. Clinical Features.

\begin{tabular}{ccccccc}
\hline Patient & $\begin{array}{c}\text { Psychological } \\
\text { Trauma }\end{array}$ & $\begin{array}{c}\text { Physical } \\
\text { Stress }\end{array}$ & Chest Pain & EKG & $\begin{array}{c}\text { Peak Troponin } \\
\text { Elevation }\end{array}$ & $\begin{array}{c}\text { Hypokinesis on } \\
\text { Ventriculography }\end{array}$ \\
\hline A & Yes ${ }^{\wedge}$ & Yes ${ }^{*}$ & Substernal & STE & 2.4 & Apical \\
B & Yes $^{\wedge}$ & No & Substernal & STD-inferior & 42 & Inferior septal wall \\
C & Yes & No & Substernal & STE & 1.8 & Apical \\
D & Yes & No & Substernal & None & 1.4 & Infero-apical \\
E & Yes & Yes & Substernal & None & 10 & Apical \\
F & No & Yes & Left Sided & None & 1.85 & Apical \\
G & No & Yes & Substernal & STE-inferior & $4.13 ; 1.79$ & Infero-apical \\
H & No & Yes & Substernal & STE-anterior & 1.39 & Infero-apical \\
I & No & Yes & Left sided & LBBB & 1.37 & Apical \\
J & Yes & No & Substernal & STE-anterior & 1.45 & Apical \\
K & Yes & No & Substernal & T-inv-inferior & 3.34 & Infero-apical \\
L & Yes & No & Substernal & T-inv-inferior & 1.5 & Infero-apical \\
& & & & ST elevation $=50 \%$ & & \\
\hline
\end{tabular}

$*=$ Argument at work; ${ }^{\wedge}=$ Congenital problem in son; ${ }^{*}=$ yard work.

The patients in our study have been followed for 5 to 17 years, with an average follow-up of $8.3 \pm 3.6$ years. In all patients, echocardiograms performed four weeks after the initial event demonstrated recovery of EF along with normalization of cardiac contraction (Table 3 ). Further yearly follow-up echocardiograms showed that patients also maintained their ejection fraction for the duration of the study. 
Table 3. Management and follow up.

\begin{tabular}{|c|c|c|c|c|c|c|}
\hline Patient & $\begin{array}{c}\text { Initial Ejection } \\
\text { Fraction } \\
\text { (Percentage) } \\
\end{array}$ & $\begin{array}{c}\text { Follow-up } \\
\text { Ejection Fraction } \\
\text { (Percentage) } \\
\end{array}$ & Administered Medications & $\begin{array}{c}\text { Follow up } \\
\text { (Years) }\end{array}$ & $\begin{array}{l}\text { Chest Pain } \\
\text { Recurrence }\end{array}$ & $\begin{array}{c}\text { Documented } \\
\text { CAD on } \\
\text { Follow-up } \\
\end{array}$ \\
\hline $\mathrm{A}$ & 45 & 70 & Aspirin, Metoprolol, Pravastatin Ramipril & 13 & Yes & No \\
\hline $\mathrm{B}$ & 50 & 60 & Metoprolol, Aspirin & 17 & No & No \\
\hline $\mathrm{C}$ & 25 & 40 & Aspirin, Metoprolol, Clopidogrel, Ramipril & 9 & No & No \\
\hline $\mathrm{D}$ & 35 & 55 & Aspirin, Lisinopril, Metoprolol, Clopidogrel & 8 & No & No \\
\hline $\mathrm{E}$ & 35 & 55 & Metoprolol, Atorvastatin & 7 & No & No \\
\hline $\mathrm{F}$ & 35 & 61 & Lisinopril, Carvedilol & 10 & Yes & No \\
\hline G & 50 & 55 & Aspirin, Clopidogrel, Valsartan, Atorvastatin & 6 & Yes & No \\
\hline $\mathrm{H}$ & 35 & 60 & Aspirin, Clopidogrel, Metoprolol, Statin & 6 & No & No \\
\hline I & 25 & 45 & Aspirin, Lisinopril, Metoprolol, Statin, & 5 & No & No \\
\hline $\mathrm{J}$ & 40 & 55 & Aspirin, Statin, Lisinopril, Amlodipine & 5 & No & No \\
\hline $\mathrm{K}$ & 30 & 50 & Aspirin, Metoprolol, Statin, Lisinopril & 5 & No & No \\
\hline $\mathrm{L}$ & 25 & 60 & Aspirin, Statin, Carvedilol, Fosinopril $* *$ & 8 & Yes & Yes \\
\hline
\end{tabular}

There were four patients who experienced recurrences of chest pain. Two patients' symptoms were musculoskeletal in etiology. One patient had a progression of $\mathrm{CAD}$, which was managed conservatively. One patient was found to have a malignant left lung mass. There was no cardiac mortality, and no recurrences of TC.

We followed the blood pressure, heart rate, body weight, and lipid panel results to ensure the patients are following optimal medical therapy and lifestyle modifications. The results are presented in Tables 4 and 5. During the follow up, one patient passed away with lung cancer. Her results will not be updated in the following tables.

After optimal, guideline-directed medical therapy (GDMT), almost all the patients had their blood pressure and heart rate controlled. The majority $(8 / 11)$ of the patients had maintained or reduced body weight. The majority of the patients $(9 / 11)$ had well-controlled LDL levels. The LDL level of patient A and patient $\mathrm{D}$ had worsened recently. Further review revealed that before these changes, their medical insurances were switched under the new healthcare law. Rosuvastatin was switched to generic Pravastatin and Atorvastatin. Follow up lipid panel results are pending.

Table 4. Changes in blood pressure, heart rate, and body weight with medical management.

\begin{tabular}{ccccccc}
\hline Patient & $\begin{array}{c}\text { Systolic Blood } \\
\text { Pressure at Diagnosis }\end{array}$ & $\begin{array}{c}\text { Most Recent Systolic } \\
\text { Blood Pressure }\end{array}$ & $\begin{array}{c}\text { Heart Rate } \\
\text { at Diagnosis }\end{array}$ & $\begin{array}{c}\text { Most Recent } \\
\text { Heart Rate }\end{array}$ & $\begin{array}{c}\text { Body Weight at } \\
\text { Presentation }\end{array}$ & $\begin{array}{c}\text { Most Recent } \\
\text { Body Weight }\end{array}$ \\
\hline A & 122 & 132 & 62 & 60 & 144 & 186 \\
B & 132 & 120 & 83 & 60 & 142 & 135 \\
C & 124 & 120 & 72 & 70 & 156 & 147 \\
D & 193 & 120 & 74 & 66 & 99 & 97 \\
E & 130 & 128 & 68 & 65 & 172 & 190 \\
F & 156 & 104 & 74 & 75 & 130 & 135 \\
\hline
\end{tabular}


Table 4. Cont.

\begin{tabular}{ccccccc}
\hline Patient & $\begin{array}{c}\text { Systolic Blood } \\
\text { Pressure at Diagnosis }\end{array}$ & $\begin{array}{c}\text { Most Recent Systolic } \\
\text { Blood Pressure }\end{array}$ & $\begin{array}{c}\text { Heart Rate } \\
\text { at Diagnosis }\end{array}$ & $\begin{array}{c}\text { Most Recent } \\
\text { Heart Rate }\end{array}$ & $\begin{array}{c}\text { Body Weight at } \\
\text { Presentation }\end{array}$ & $\begin{array}{c}\text { Most Recent } \\
\text { Body Weight }\end{array}$ \\
\hline G & 140 & 111 & 72 & 84 & 115 & 111 \\
H & 116 & 106 & 117 & 98 & 182 & 145 \\
I & 167 & 141 & 85 & 83 & 266 & 266 \\
J & 131 & 128 & 62 & 72 & 149 & 140 \\
K & 135 & 128 & 102 & 80 & 356 & 270 \\
L & 117 & 125 & 90 & 78 & 164 & 175 \\
\hline
\end{tabular}

Table 5. Lipid panel results after medical management.

\begin{tabular}{ccccccccc}
\hline Patient & $\begin{array}{c}\text { Initial } \\
\text { Cholesterol }\end{array}$ & $\begin{array}{c}\text { Most Recent } \\
\text { Cholesterol }\end{array}$ & $\begin{array}{c}\text { Initial } \\
\text { LDL }\end{array}$ & $\begin{array}{c}\text { Most Recent } \\
\text { LDL }\end{array}$ & $\begin{array}{c}\text { Initial } \\
\text { HDL }\end{array}$ & $\begin{array}{c}\text { Most Recent } \\
\text { HDL }\end{array}$ & $\begin{array}{c}\text { Initial } \\
\text { Triglycerides }\end{array}$ & $\begin{array}{c}\text { Most Recent } \\
\text { Triglycerides }\end{array}$ \\
\hline A & 169 & 197 & 71 & 112 & 59 & 53 & 124 & 159 \\
B & 164 & 140 & 80 & 60 & 65 & 66 & 91 & 71 \\
C & 159 & 145 & 90 & 73 & 61 & 58 & 76 & 86 \\
D & 164 & 202 & 87 & 127 & 60 & 59 & 85 & 77 \\
E & 212 & 154 & 135 & 95 & 52 & 56 & 168 & 204 \\
F & 153 & 155 & 101 & 93 & 37 & 46 & 72 & 80 \\
G & 168 & 171 & 73 & 79 & 82 & 79 & 61 & 64 \\
H & 172 & 142 & 113 & 63 & 19 & 26 & 202 & 173 \\
I & 168 & 154 & 99 & 81 & 32 & 36 & 187 & 183 \\
J & 151 & 121 & 73 & 59 & 30 & 19 & 238 & 202 \\
K & 154 & 180 & 66 & 74 & 36 & 58 & 258 & 302 \\
L & 119 & 107 & 54 & 37 & 50 & 35 & 75 & 174 \\
\hline
\end{tabular}

LDL $=$ Low Density Lipoprotein; HDL = High Density Lipoprotein .

\section{Discussion}

TC is increasingly recognized in the differential diagnosis of acute coronary syndrome (ACS) as a cause of myocardial infarction with normal coronary arteries (MINCA) [1]. Numerous studies document the short-term recovery of TC patients. A meta-analysis of 28 case series by Pilgrim et al., showed complete recovery of EF in $95.9 \%$ of patients in 7-37 days, with ejection fraction improving from $20 \%-49.9 \%$ to $59 \%-76 \%$ [2]. Few studies, however, followed the long-term course of these patients.

The few studies following long-term outcomes in TC patients arrive at differing conclusions regarding prognosis. Elesber et al., and Valbusa et al., both tracked overall survival in age and gendermatched TC populations, but found no difference. In contrast, Sharkey et al., and Ionesco et al., found that survival in TC patients was reduced [3-6]. Importantly, all of the aforementioned studies showed high cardiovascular event rates following the initial insult. In the follow-up by Elesber et al. during the $4.7 \pm 4.8$ years follow-up, $17 \%$ of patients suffered mortality, $10 \%$ of patients suffered recurrence of $\mathrm{TC}$, and $12 \%$ of patients suffered re-hospitalization for cardiac reasons, for a total $39 \%$ event rate [5]. Ionesco et al. also saw this high event rate in their follow-up of 27 TC patients over a mean of $27 \pm 16$ months. $52 \%$ of patients reached a primary end point of a combination of all-cause death, cardiogenic shock, sudden cardiac death, and re-hospitalization for cardiac reasons, with the authors 
concluding that the long-term outcome of TC is worse than previously reported [3]. In a recent study, spectroscopy and imaging done four months after the initial TC event showed cardiac energetic impairment, adding more evidence of the long term impairment in health and well-being of TC patients [7].

In a recent prospective study by Looi et al., 26\% of patients had a complicated hospital course, 4\% need circulatory support with an intra-aortic balloon pump, $6 \%$ need ventilatory support, $2 \%$ inhospital mortality, and an additional $4 \%$ mortality soon after hospital discharge [8].

Meta-analysis by Singh et al., 2014, showed that the in-hospital mortality rate of TC was $4.5 \%$, but only $38 \%$ of the mortality was directly related to TC and complications. The remaining $62 \%$ of the mortality was due to underlying non-cardiac mortality. It brought the cardiac mortality from TC down to $1.5 \%$ [9].

In comparison, we found a trend towards a decrease in morbidity and mortality of TC patients who were prescribed cardiac medical therapy on discharge, indicating a possible benefit from a long-term management strategy (Table 6).

Table 6. Comparing the Data from Previous Studies.

\begin{tabular}{|c|c|c|c|c|}
\hline & Ionesco et al. & Elesber et al. & Khalighi et al. & Looi et al. 2012 \\
\hline Number of Patients & 27 & 100 & 12 & 100 \\
\hline Mean Age (years) & $68 \pm 14$ & $66 \pm 13$ & $64 \pm 15$ & $65 \pm 11$ \\
\hline Follow/up Duration & $2.25 \pm 1.3$ years & $4.7 \pm 4.2$ years & $8.3 \pm 3.6$ years & $3.0 \pm 1.7$ \\
\hline Patients Antiplatelet agent & $33 \%$ & $50 \%$ & $83 \%$ & 90 \\
\hline Patients on BB & $33 \%$ & $51 \%$ & $83 \%$ & $65 \%$ \\
\hline Patients on ACE I/ARB & $41 \%$ & $74 \%$ & $83 \%$ & $63 \%$ \\
\hline Patients on Statin & $30 \%$ & $32 \%$ & $67 \%$ & $69 \%$ \\
\hline $\begin{array}{c}\text { Overall patients on } \\
\text { optimal medical therapy }\end{array}$ & $34.3 \%$ & $51.8 \%$ & $79.0 \%$ & \\
\hline \multicolumn{5}{|c|}{ Results } \\
\hline Chest pain & 2 & 31 & 4 & $78 \%$ \\
\hline $\begin{array}{l}\text { Hospitalization for } \\
\text { cardiac complaints }\end{array}$ & 8 & 12 & 1 & $26 \%$ \\
\hline Recurrence of TC & 2 & 10 & 0 & $7(7 \%)$ \\
\hline Mortality & 4 & 17 & 0 & $4(4 \%)$ \\
\hline Morbidity/Mortality & $14(52 \%)$ & $29(29 \%) *$ & $1(8 \%)$ & $26(26 \%)$ \\
\hline
\end{tabular}

Medical therapy was targeted at preventing the mechanisms believed to cause TC:

(1) Cardioselective beta blockers (carvedilol, metoprolol) to prevent myocardial stunning or microinfarction caused by catecholamine-induced sympathetic overdrive: Wittstein et al., showed that catecholamine levels are 2-4 times higher in patients with stress-induced cardiomyopathy as compared to patients with myocardial infarction. [10] This is the most widely accepted mechanism leading to TC $[10,11]$. 
(2) Cardioselective beta-blockers, Calcium channel blockers and/or ACE-I/ARB may prevent coronary artery spasm-Lacy et al. [12] showed that stress from public speaking can lead to vasoconstriction of coronary artery segments. Kiuriso et al. demonstrated that three of 30 patients with TC had spontaneous multivessel epicardial coronary spasm on angiography, and 10 of 14 patients with TC had coronary spasms on a provocation test using either egonovine or acetylcholine.

(3) Statins and anti-platelet agents to prevent microvascular dysfunction leading to transient thrombosis [2,13]. In a study of 16 patients with TC, Bybee showed that all 16 patients had decreased coronary blood flow in at least one epicardial vessel and 10 patients had this in all three epicardial vessels [14]. In one of the earlier studies of TC, Sadamatsu et al. [13] studied the angiography of two patients with TC and found that both had reduced coronary flow reserve.

In cross-analysis with TC patients, followed long-term in other studies, we observed a negative correlation between the percentage of patients on cardiac medications and the subsequent adverse event rate. In contrast to previous studies, most patients in our study were placed on appropriate cardiac medications at the time of discharge (Table 6). They maintained their ejection fraction with only one patient requiring readmission for progression of CAD. Over a long period of follow-up, our patients did well with medical management, including TLC and GDMT. This suggests that aggressive risk factor reduction by medical management might explain the difference in long term prognosis of TC patients seen in these studies.

\section{Limitations}

This is a single center trial with a limited number of patients without any control group. However, our study has the longest documented follow-up to prove the benefit of long-term medical management. However, due to limited power, we cannot specify which medication produced the greatest benefit.

Our results might also be compounded by selection bias since we followed 12 patients with Takotsubo Cardiomyopathy after discharge from hospital. We selected only the survivors. All of our patients survived the initial hospitalization. The biggest limiting factor to any conclusive statement regarding long-term prognosis and management is the relatively small number of patients available for such an analysis. As the diagnosis becomes more prevalent, future studies may be able to access a larger patient population for greater power.

\section{Conclusions}

TC patients may be at risk of experiencing long-term cardiovascular events. Following 12 TC patients with TLC and GDMT, we observed recovery and maintenance of the ejection fraction, no cardiac mortality, and an excellent long-term prognosis. Risk factor reduction with TLC and GDMT may be effective in reducing the risk of long-term cardiovascular morbidity and mortality in TC patients.

\section{Acknowledgments}

There has been no financial support or assistance for this project. 


\section{Author Contributions}

Koroush Khalighi MD FACC, FACP, FCCP — involved in conception and design, critical revision of manuscript; Thein Tun Aung MD-involved in acquisition of data, drafting of manuscript and critical revision of manuscript; Swe Oo MD — involved and in acquisition of data; Mohammad Farooq MD - involved in conception and design, acquisition of data, analysis and interpretation of data, drafting of manuscript. Informed consent was taken from all patients to conduct this retrospective chart review. These charts are outpatient records, from the private clinic of the corresponding author.

\section{Conflicts of Interest}

The authors declare no conflict of interest.

\section{References}

1. Seth, P.S.; Aurigemma, G.P.; Krasnow, J.M.; Tighe, D.A.; Untereker, W.J.; Meyer, T.E. A syndrome of transient left ventricular apical wall motion abnormality in the absence of coronary disease: A perspective from the United States. Cardiology 2003, 100, 61-66.

2. Pilgrim, T.M.; Wyss, T.R. Takotsubo cardiomyopathy or transient left ventricular apical; ballooning syndrome: A systematic review. Int. J. Cardiol. 2008, 124, 283-292.

3. Ionescu, C.N.; Aguilar-Lopez, C.A.; Sakr, A.E.; Ghantous, A.E.; Donohue, T.J. Long-term outcome of Tako-tsubo cardiomyopathy. Heart Lung Circ. 2010, 19, 601-605.

4. Valbusa, A.; Abbadessa, F.; Giachero, C.; Vischi, M.; Zingarelli, A.; Olivieri, R.; Visconti, L.O. Long-term follow-up of Tako-Tsubo-like syndrome: A retrospective study of 22 cases. J. Cardiovasc. Med. 2008, 9, 805-809.

5. Elesber, A.A.; Prasad, A.; Lennon, R.J.; Wright, R.S.; Lerman, A.; Rihal, C.S. Four-year recurrence rate and prognosis of the apical ballooning syndrome. J. Am. Coll. Cardiol. 2007, 50, 448-452.

6. Sharkey, S.W.; Windenburg, D.C.; Lesser, J.R.; Maron, M.S.; Hauser, R.G.; Lesser, J.N.; Haas, T.S.; Hodges, J.S.; Maron, B.J. Natural history and expansive clinical profile of stress (tako-tsubo) cardiomyopathy. J. Am. Coll. Cardiol. 2010, 55, 333-341.

7. Dawson, D.K.; Neil, C.J.; Henning, A.; Cameron, D.; Jagpal, B.; Bruce, M.; Horowitz, J.; Frenneaux, M.P. Tako-Tsubo Cardiomyopathy: A Heart Stressed Out of Energy? JACC Cardiovasc. Imaging 2015, 8, 985-987.

8. Looi, J.L.; Wong, C.W.; Khan, A.; Webster, M.; Kerr, A.J. Clinical characteristics and outcome of apical ballooning syndrome in Auckland, New Zealand. Heart Lung Circ. 2012, 21, 143-149.;

9. Singh, K.; Carson, K.; Usmani, Z.; Sawhney, G.; Shah, R.; Horowitz, J. Systematic review and meta-analysis of incidence and correlates of recurrence of takotsubo cardiomyopathy. Int. J. Cardiol. 2014, 174, 696-701.

10. Wittstein, I.S.; Thiemann, D.R.; Lima, J.A.; Baughman, K.L.; Schulman, S.P.; Gerstenblith, G.; Thiemann, D.R.; Lima, J.A.; Baughman, K.L.; Schulman, S.P.; et al. Neurohumoral features of myocardial stunning due to sudden emotional stress. N. Engl. J. Med. 2005, 352, 539-548. 
11. Coupez, E.; Eschalier, R.; Pereira, B.; Pierrard, R.; Souteyrand, G.; Clerfond, G.; Citron, B.; Lusson, J.R.; Mansencal, N.; Motreff, P. A single pathophysiological pathway in Takotsubo cardiomyopathy: Catecholaminergic stress. Arch. Cardiovasc. Dis. 2014, 107, 245-252.

12. Lacy, C.R.; Contrada, R.J.; Robbins, M.L.; Tannenbaum, A.K.; Moreyra, A.E.; Chelton, S.; Kostis, J.B. Coronary vasoconstriction induced by mental stress (simulated public speaking). Am. J. Cardiol. 1995, 75, 503-505.

13. Dorfman, T.A.; Iskandrian, A.E. Takotsubo cardiomyopathy: State-of-the-art review. J. Nucl. Cardiol. 2009, 16, 122-134.

14. Bybee, K.A.; Prasad, A.; Barsness, G.W.; Lerman, A.; Jaffe, A.S.; Murphy, J.G.; Wright, R.S.; Rihal, C.S. Clinical characteristics and thrombolysis in myocardial infarction frame counts in women with transient left ventricular apical ballooning syndrome. Am. J. Cardiol. 2004, 94, 343-346.

(C) 2015 by the authors; licensee MDPI, Basel, Switzerland. This article is an open access article distributed under the terms and conditions of the Creative Commons Attribution license (http://creativecommons.org/licenses/by/4.0/). 